Journal of Balkumari College

ISSN : 2467-9321 Website: http://www.nepjol.info/index.php/jbkc

Volume : 9, Issue : 1, June 2020, Page No.: 25-33

\title{
Knowledge Management Enablers for Knowledge Creation Combination in Nepalese Hospitality Industry
}

\author{
Dr. Pushpa Maharjan* \\ Assistant Professor \\ Public Youth Campus, Faculty of Management \\ Tribhuvan University
}

\begin{abstract}
This paper examines the relationships between the knowledge management enablers and knowledge creation combination in the hospitality industry such as hotel, travel and trekking agencies in Nepal. The study is based on primary data with 382 responses. The self-administered questionnaires were used to collect the perceptive opinions from the respondents. The study concludes that the key knowledge management enablers such as collaboration, trust, learning, and information technology do influence to the knowledge creation combination positively. Managers should promote collaboration, trust, learning and information technology facilities for employees to create knowledge in organisation.
\end{abstract}

\section{INTRODUCTION}

Combination (explicit to explicit knowledge) is part of the process that synthesizes explicit concepts and brings them to a knowledge base through the following procedures (Nonaka\& Konno, 1998): capture and integrating new essential explicit knowledge, through collection, reflection and synthesis; dissemination of this one through the transfer process commonly used in the organisation, such presentations, meetings or emails; and processing by documents, plans, reports and market data. Thus, externalisation needs combination "to embody knowledge in a form that is concrete enough to facilitate further knowledge creation in a wider social context" (Nonaka et al., 1994). In combination the knowledge from externalisation is shared within the organisation, thus new superior explicit knowledge is disseminated in the company (Nonaka\& Konno, 1998). The combination activities edit and integrate knowledge from externalisation by using documents or databases to generate new knowledge application (Li et al., 2009). Firms can use a combination process to create new knowledge from the existing knowledge from externalisation and generate new knowledge application (Nonaka et al., 2000).

Cyber ba referred to a virtual space of interaction and corresponds to the combination mode of knowledge creation. Data warehousing and data mining, documents repositories, and software agents, for example, may be of great value in cyber ba (Alavi\&Leidner, 2001). Generation of new explicit knowledge through categorization, synthesis, combination and integration into existing knowledge structures (Kuhlen, 2003). An individual can also combine discrete pieces of explicit knowledge into a new whole. For example, when a comptroller of a company collects information from throughout the organisation and puts it together in a financial report, that report is new knowledge in the sense that it synthesizes information from many different sources (Nonaka, 2008).

Nonaka and Takeuchi (1995) posited that combination gives way to 'systemic knowledge', for instance prototypes or new constituent technologies. Combination converts explicit knowledge gathered from indoors or outdoors into further intricate and organized explicit knowledge that possibly will materialize into action and practice (Li et al., 2009). Hence, combination gives birth to new products or technologies that can benefit new product development and is more likely to produce outcomes that are more applicable to be put in practice.

Choi (2002), Lee and Choi (2000), Berraies et al. (2014), and Migdadi (2005) found that collaboration does not affect the combination mode. Choi (2002), Lee and Choi (2000), and Migdadi (2005) found that trust is a significant predictor to knowledge creation combination. But, Berraies et al. (2014) found that trustis notpositively significant related with combination. Choi (2002), Lee and Choi (2000), Berraies et al. (2014), and Migdadi (2005)

$\bar{*}$ Corresponding author: s3pushpam@gmail.com 
found that learning does not affect the combination mode. Choi (2002), Lee and Choi (2000), and Migdadi (2005) concluded that the centralisation does not affect combination viewpoint. But Berraies et al. (2014) found that centralisation is negatively related to combination. Choi (2002), Lee and Choi (2000), and Migdadi (2005) found that formalisation does not significantly affect combination. But Berraies et al. (2014) found that formalisation has a positive impact on combination. Choi (2002), Lee and Choi (2000), Berraies et al. (2014), and Migdadi (2005) found that information technology is a significant predictor for combination.

Chaudhary (2016) stated that the use of computer as a major mode of knowledge transfer is high in Nepalese banks, which means that the banks codify knowledge in systematic and standardized way, in database for easy access. Chalise (2011) suggested that Nepalese banking sector organisation should be aware in conducting regular staff meeting with employees, managers try to find out employees, true feeling, they should survey employees regularly to assess their attitudes towards work. He also revealed that industry should be aware in circulating the documents about their business to external stakeholders, and keeps a database of customer information that is easy to access. Kandel (2015) suggested that Nepal telecom industry should be aware in circulating the documents about their business to external stakeholder and keeps a database of customer information that is easy to access.

\section{REVIEW OF LITERATURE}

A variety of knowledge management enablers have been addressed in the literature (Ichijo et al., 1998; Leonard-Barton, 1995; Sawhney\&Prandelli, 2000). Among these enablers, organisational culture, structure and information technology are incorporated into this research model. Culture can be defined as unique system within which values are shared and the comportment of employees is constructed accordingly (Jeng\& Dunk, 2013). For the successful implementation of knowledge management, organisational culture is one of the most important considerations (Davenport \&Prusak, 1998; Demarest, 1997; Gold et al., 2001).

Nejatian et al. (2013) stated that organisational culture which consists of cooperation, trust, and learning variables is found to be the most effective enabler among KMEs. This reveals an important point: all knowledge management programs are strongly dependent on organisational culture. An organisation with inappropriate cultural environment is likely to fail in its knowledge management programs or improving its organisational performance.

Fahey and Prusak (1998) defined that collaboration between team members also tightens individual differences which can help shape a shared understanding about the organisation's environments through supportive and reflective communication. Without shared understanding among team members, very few knowledge creation activities are conducted (Fahey \&Prusak, 1998; Lee \& Choi, 2003). From a knowledge governance perspective, work arrangements that allow people to work in groups serve as a potent facilitator of knowledge sharing. Following Cook and Brown's (1999) line of reasoning, group-based work affords sharing of knowledge among organisational members. Be it story telling among members of communities of practice (Brown \&Duguid, 2000) or group discussion among members based on brainstorming or brain-writing (Paulus \& Yang, 2000), the outcome is the sharing of knowledge. In communities of practice, less experienced members learn from experts in the field (Ardichvili et al.,2006) and personal experiences of individual community members merge to form a comprehensive understanding of the business problem at hand (Wenger \& Snyder, 2000).

Mutual trustexists in an organisation when its members believe in the integrity, character and ability of each other (Robbins, 1998; Robbins et al., 2001). When knowledge exchange activities can be increased via mutual trust, knowledge creation occurs (Lee \& Choi, 2003; Takeuchi \&Nonaka, 2004). Trust encourages an environment that promotes knowledge creation as it reduces the fear of risk. Hence, high levels of trust can reduce this risk in teams (Lee \& Choi, 2003). When team members trust one another, they are less apprehensive to share ideas and thoughts with each other, sparking off a spiral of knowledge creation through the SECI process (Takeuchi \&Nonaka, 2004). However, Robbins (1998) concluded that although trust may take a long time to build, it can be easily destroyed and would therefore require careful attention by management.

Intellectual organisations seem to develop a deeply ingrained learning culture (Quinn et al., 1996). For successful knowledge creation, individuals should be encouraged to ask questions (Ndlela\&Toit, 2001). Knowledge creation capacity is increased by various learning means such as education, training, and mentoring (Narasimha, 
2000). The mere presence of traditional training and development activities may not be sufficient. Those organisations which are serious about knowledge creation need to support a continuous learning environment (Ndlela\&Toit, 2001). Learning should happen at all levels of the organisation structure. Individuals must be encouraged to ask questions, to challenge and to learn. This continuous learning opens up the possibility of achieving scale in knowledge creation. Nucor, which has been the most innovative steel company in the U.S., built a knowledge creation foundation by investing in continuous and multifunctional training programs (Gupta \&Govindarajan, 2000).

Centralisation implies the location of decision authority and control within an organisation. The centralisation of decision making authority inevitably reduces creative solutions. Scattering the decision making power facilitates spontaneity, experiment, and expressional freedom. These are the critical forces of knowledge creation. Thus, many researchers believe that a centralisedorganisation structure makes knowledge creation harder (Nevis et al., 1995; Nonaka\& Takeuchi, 1995; O’Dell \& Grayson, 1999). Zaltman (1986) stated that in a less centralisedorganisation structure, more knowledge is created. In addition, centralised structure prevents free interdepartmental communication and sharing of ideas due to the high amount of time spent on communication channels (Raven \&Prasser, 1996). It also causes falsification and standing of ideas (Nonaka\& Takeuchi, 1995).

Formalisation refers to the degree to which decisions and working relationships are managed by formal rules, procedures, and standard policies (Chase, 1998; Hopper, 1990; Zuckeret al., 1996). Knowledge creation requires flexibility rather than work rules (Bennett \& Gabriel, 1999). It seems that when strict formal rules dominate an organisation, the range of new ideas shrinks. Thus, flexibility can provide better ways of doing things (Nelson \&Cooprider, 1996). When flexibility increases in an organisation structure, knowledge creation tends to increase as well. Knowledge creation also requires variation. In order to be more adaptable when confronting unexpected problems, an organisation may accommodate variation in both of its processes and structure (Kreitner\&Kinicki, 1992).

Properly use of information technology can accelerate knowledge management (Mohamed, Stankosky\& Murray, 2006). The implementation of knowledge management technologies without ensuring that the organisations employees are well informed about the organisation's overall goals and objectives, and how this technology can facilitate the success of these goals, will lead to disappointing returns on the technology investment (Curley \&Kivowitz, 2001). They concluded that IT technology in particular, has a vital role in knowledge management. It serves knowledge management throughout all the knowledge management steps. It provides the means to capture knowledge, to store, organize and access, as well as to share knowledge.

Combination involves the establishment of innovative knowledge by substitutions and integrations in explicit knowledge possessed by employees (Bolloju et al., 2002). Vaccaro et al. (2009) suggested that the combination process results in novel explicit knowledge via the integration, classification, reclassification and synthesis of current explicit knowledge. Thus, combination initiatives are mechanized in order to efficiently manage explicit knowledge such that it is in a more systematic and structured condition to be reviewed by employees.

\section{Knowledge Management Enablers for Knowledge Creation Combination}

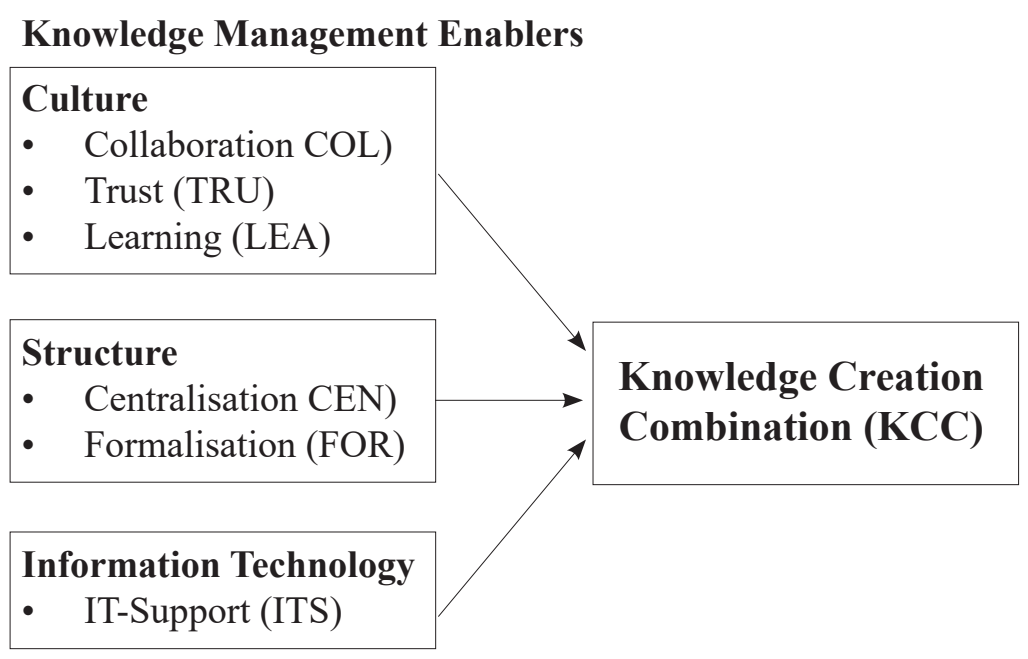




\section{RESEARCH METHOD}

To examine knowledge management enablers for knowledge creation combination in Nepalese hospitality industry, the study used the descriptive research design based on the survey. The quantitative research design is applied to develop an understanding of the research issue.

The study has used primary data collected from executives, managers, department heads, sales officers, marketing officers, finance officers, guest relation officers, public relation officers and human resource managers in the hospitality industry organisations. In the process of gathering information, a set of structured questionnaire was used as the main instrument. The primary data were collected by 'delivery and collection' methods.

The total of 458 responses was collected from 97 firms. Due to incomplete data, 76 responses were eliminated. Consequently, 382 responses from 97 firms were taken for further analysis. The total response rate was 83 per cent. Self-administered questionnaires were used to collect the perceptive opinions from the respondents.

Questionnaire items developed included a list of 52 items to measure the different constructs in the study: collaboration, trust, learning, centralisation, formalisation, information technology and knowledge creation combination. The development of the items was done by re-evaluating intensively the literature review related to the concepts and constructs stated in the integrative view. The aim of this empirical research is to test whether the dimensions proposed in the above-mentioned integrative view support a significant distinction between different kinds of knowledge management enablers.

To validate the proposed research model, this study conducted a pre-test. The pre-test was conducted in the month of November, 2014. For the pre-test survey, this study developed questionnaire and collected data from 36 potential respondents of the selected samples: both hotels (20) and travel/trekking agencies of 16 respondents. Based on the findings of the pre-test survey, research questionnaire was modified to improve reliability and validity of the study. After the pre-test, the questionnaire was finalised and the main study was conducted.

The study used regression analysis to test the interrelationship of knowledge management enablers (independent variables) similarly their impact on knowledge creation combination(dependent variables). The application of regression analysis to the present study is desirable as they significantly help researchers evaluate the causal effect of one variable on other variables.

\section{RESULTS \\ Hypotheses}

The study hypotheses were largely derived from theoretical statements made in the literature on knowledge management. In the first hypothesis, the study analyzed the collaboration dimension of knowledge management enabler. In the second and third hypotheses, the study analyzed the trust and learning dimension. In the fourth, fifth and six hypotheses, the study analyzed the centralisation, formalisation and information technology support dimension.

\section{Hypothesis 1: Collaboration}

The study proposes to analyse the collaboration for knowledge creation combination. The following hypotheses have been formulated:

Null hypothesis, $H_{0}$ : Collaboration does not affect knowledge creation combination. Alternative hypothesis, $H_{I}$ : Collaboration affects knowledge creation combinationpositively.

The acceptance of alternative hypothesis associated with hypothesis 1 implies that collaboration will have positive effect on the knowledge creation combination and it points to the effective role of collaboration on knowledge creation combination. On the other hand, if the tests reject the alternative hypotheses and it may suggest that the collaboration is not helpful for knowledge creation combination.

\section{Hypothesis 2: Trust}

After determination of the collaboration for knowledge creation combination, the study proposes to evaluate the trust dimension of knowledge creation combination. To test the trust for knowledge creation combination, the 
testable hypotheses have been formulated:

Null hypothesis, $H_{0}$ : Trust does not affect knowledge creation combination.

Alternative hypothesis, $H_{2}$ : Trust affects knowledge creation combination positively.

The acceptance of alternative hypothesis associated with hypothesis 2 implies that trust will have positive effect on the knowledge creation combination and it points to the effective role of trust on knowledge creation combination. On the other hand, if the tests reject the alternative hypotheses and it may suggest that the trust does not play important role for knowledge creation combination.

\section{Hypothesis 3: Learning}

After determination of the trust for knowledge creation combination, the study proposes to evaluate the learning for knowledge creation combination. To test the learning for knowledge creation combination, the testable hypotheses have been formulated:

Null hypothesis, $H_{0}$ : Learning does not affect knowledge creation combination.

Alternative hypothesis, $H_{3}$ : Learning affects knowledge creation combination positively.

The acceptance of alternative hypothesis associated with hypothesis 3 implies that learning will have positive effect on the knowledge creation combination and it points to the effective role of learning on knowledge creation combination. On the other hand, if the tests reject the alternative hypotheses and it may suggest that the learning does not play important role for knowledge creation combination.

\section{Hypothesis 4: Centralisation}

After determination of the learning for knowledge creation combination, the study proposes to evaluate the centralisation for knowledge creation combination. To test the centralisation for knowledge creation combination, the testable hypotheses have been formulated:

Null hypothesis, $H_{0}$ : Centralisation does not affect knowledge creation combination. Alternative hypothesis, $H_{4}$ : Centralisation affects knowledge creation combination negatively.

The acceptance of alternative hypothesis associated with hypothesis 4 implies that centralisation will have negative effect on the knowledge creation combination and it points to the negative effect of centralisation for knowledge creation combination. On the other hand, if the tests reject the alternative hypotheses and it may suggest that the centralisation does not play important role for knowledge creation combination.

\section{Hypothesis 5: Formalisation}

After determination of the centralisation for knowledge creation combination, the study proposes to evaluate the formalisation for knowledge creation combination. To test the formalisation for knowledge creationcombination, the testable hypotheses have been formulated:

Null hypothesis, $H_{0}$ : Formalisation does not affect knowledge creation combination.

Alternative hypothesis, $H_{5}$ : Formalisation affects knowledge creation combinationnegatively.

The acceptance of alternative hypothesis associated with hypothesis 5 implies that formalisation will have negative effect on the knowledge creation combination and it points to the negative effect of formalisation for knowledge creation combination. On the other hand, if the tests reject the alternative hypotheses and it may suggest that the formalisation does not play important role for knowledge creation combination.

\section{Hypothesis 6: IT Support}

After determination of the formalisation for knowledge creation combination, the study proposes to evaluate the IT support for knowledge creation combination. To test the IT support for knowledge creation combination, the testable hypotheses have been formulated: 
Null hypothesis, $H_{0}$ : IT support does not affect knowledge creation combination.

Alternative hypothesis, $H_{6}$ : IT support affects knowledge creation combination positively.

The acceptance of alternative hypothesis associated with hypothesis 6 implies that IT support will have positive effect on the knowledge creation combination and it points to the effective role of IT support for knowledge creation combination. On the other hand, if the tests reject the alternative hypotheses and it may suggest that the IT support does not play important role for knowledge creation combination.

\section{Regression Equation Model between KCC and KMEs} as follows:

Regression equation between the knowledge creation combination and knowledge management enablers

$\mathrm{KCC}=\alpha+\beta_{1} \mathrm{COL}+\beta_{2} \mathrm{TRU}+\beta_{3} \mathrm{LEA}+\beta_{4} \mathrm{CEN}+\beta_{5} \mathrm{FOR}+\beta_{6} \mathrm{ITS}+\mathrm{E}$

Where,

$\mathrm{KCC}=$ knowledge creation combination

$\alpha \quad=$ constant number

$\beta_{1} \quad=$ change in knowledge creation combination associated with unit change in collaboration

$\beta_{2} \quad=$ change in knowledge creation combination associated with unit change in trust

$\beta_{3}=$ change in knowledge creation combination associated with unit change in learning

$\beta_{4} \quad=$ change in knowledge creation combination associated with unit change in centralisation

$\beta_{5}=$ change in knowledge creation combination associated with unit change in formalisation

$\beta_{6}=$ change in knowledge creation combination associated with unit change in information technology

$\mathrm{COL}=$ collaboration

TRU $=$ trust

LEA $=$ learning

$\mathrm{CEN}=$ centralisation

$\mathrm{FOR}=$ formalisation

ITS = information technology

$\mathrm{E} \quad=$ prediction error (residual)

\section{Table Estimated Relationship between KCC and Fundamental Variables}

The results are based on pooled cross-sectional data of 97 enterprises with 382 observations by using linear regression model. The model is, KCC $=\alpha+\beta_{1} C O L+\beta_{2} T R U+\beta_{3} L E A+\beta_{4} C E N+\beta_{5} F O R+\beta_{6} I T S+E$. Where, KCC, COL, TRU, LEA, CEN, FOR and ITS are knowledge creation combination, collaboration, trust, learning, centralisation, formalisation and information technology respectively. Results for various subsets of independent variables are presented as well.

\begin{tabular}{|c|c|c|c|c|c|c|c|c|c|c|c|}
\hline \multirow{2}{*}{ Models } & \multirow{2}{*}{ Intercept } & \multicolumn{6}{|c|}{ Regression Coefficients of } & \multirow{2}{*}{$\mathbf{R}^{2}$} & \multirow{2}{*}{$\begin{array}{c}\text { Adjusted } \\
\mathbf{R}^{2}\end{array}$} & \multirow{2}{*}{ F } & \multirow{2}{*}{ DW } \\
\hline & & COL & TRU & LEA & CEN & FOR & ITS & & & & \\
\hline 1 & $\begin{array}{l}1.656 \\
(000)^{*}\end{array}$ & $\begin{array}{c}0.679 \\
(000)^{*}\end{array}$ & & & & & & 0.417 & 0.416 & $\begin{array}{c}272.333 \\
(000)^{*}\end{array}$ & 2.001 \\
\hline 2 & $\begin{array}{l}2.656 \\
(000)^{*}\end{array}$ & & $\begin{array}{l}0.491 \\
(000)^{*}\end{array}$ & & & & & 0.234 & 0.232 & $\begin{array}{l}116.148 \\
(000)^{*}\end{array}$ & 1.714 \\
\hline 3 & $\begin{array}{l}2.135 \\
(000)^{*}\end{array}$ & & & $\begin{array}{l}0.630 \\
(000)^{*}\end{array}$ & & & & 0.387 & 0.385 & $\begin{array}{c}239.465 \\
(000)^{*}\end{array}$ & 1.812 \\
\hline 4 & $\begin{array}{l}5.070 \\
(000)^{*}\end{array}$ & & & & $\begin{array}{c}0.027 \\
(0.465)\end{array}$ & & & 0.001 & -0.001 & $\begin{array}{c}0.535 \\
(0.465)\end{array}$ & 1.495 \\
\hline 5 & $\begin{array}{l}5.252 \\
(000)^{*}\end{array}$ & & & & & $\begin{array}{l}-0.026 \\
(0.482)\end{array}$ & & 0.001 & -0.001 & $\begin{array}{c}0.496 \\
(0.482)\end{array}$ & 1.510 \\
\hline
\end{tabular}




\begin{tabular}{|c|c|c|c|c|c|c|c|c|c|c|c|}
\hline 6 & $\begin{array}{l}2.438 \\
(000)^{*}\end{array}$ & & & & & & $\begin{array}{c}0.557 \\
(000)^{*}\end{array}$ & 0.330 & 0.329 & $\begin{array}{c}187.555 \\
(000)^{*}\end{array}$ & 1.579 \\
\hline 7 & $\begin{array}{c}1.223 \\
(000)^{*}\end{array}$ & $\begin{array}{c}0.435 \\
(000)^{*}\end{array}$ & $\begin{array}{c}0.005 \\
(0.927)\end{array}$ & $\begin{array}{c}0.347 \\
(000)^{*}\end{array}$ & & & & 0.483 & 0.479 & $\begin{array}{c}117.612 \\
(000)^{*}\end{array}$ & 1.960 \\
\hline 8 & $\begin{array}{l}5.170 \\
(000)^{*}\end{array}$ & & & & $\begin{array}{c}0.076 \\
(0.115)\end{array}$ & $\begin{array}{l}-0.078 \\
(0.118)\end{array}$ & & 0.008 & 0.003 & $\begin{array}{c}1.498 \\
(0.225)\end{array}$ & 1.486 \\
\hline 9 & $\begin{array}{c}0.924 \\
(000)^{*}\end{array}$ & $\begin{array}{c}0.325 \\
(000)^{*}\end{array}$ & $\begin{array}{c}-0.009 \\
(0.852)\end{array}$ & $\begin{array}{c}0.299 \\
(000)^{*}\end{array}$ & $\begin{array}{l}-0.007 \\
(0.821)\end{array}$ & $\begin{array}{c}-0.050 \\
(0.141)\end{array}$ & $\begin{array}{c}0.281 \\
(000)^{*}\end{array}$ & 0.547 & 0.540 & $\begin{array}{l}75.494 \\
(000)^{*}\end{array}$ & 1.857 \\
\hline
\end{tabular}

Source : Questionnaire survey, 2015

Notes : (1) Figures in parentheses are p-values.

(2) * and ** denote that the results are significant at 1 percent and 5 percent level of significance respectively.

The regression results of knowledge creation combination on collaboration, trust, learning, centralisation, formalisation, and information technology. The alternative specifications of the models reveal the positive relationship of knowledge creation combination with collaboration, trust, learning and information technology, whereas, insignificant relationship of the knowledge creation combination with centralisation and formalisation. Models 1 to 3 show that, there is a significant relationship between the knowledge creation combination on collaboration, trust and learning.

The knowledge creation combination is positively influenced by collaboration, trust, learning, and information technology, and not significantly influenced by centralization andformalisation. The overall results show the positive relationship of knowledge creation combination with collaboration, trust, learning, and information technology, and not with centralisation and formalisation.

\section{CONCLUSION}

The study has concluded that the key knowledge management enablers such as collaboration, trust, learning, and information technology do influence to the knowledge creation combination positively. It indicates that the collaborative culture encourages to capture and integrating new essential knowledge. But the study result contradicts with Choi (2002), Lee and Choi (2000), Berraies et al. (2014) and Migdadi (2005), which found that collaboration, does not affect the combination mode. The result is consistent with Choi (2002), Lee and Choi (2000), and Migdadi (2005). But the study result contradicts with Berraies et al. (2014), which found that trustis nota positively significant related with combination. However, the study result contradicts with Choi (2002), Lee and Choi (2000), Berraies et al. (2014) and Migdadi (2005), they found that learning does not affect the combination mode.The result is consistent with Choi (2002), Lee and Choi (2000) and Migdadi (2005) with combination viewpoint. But Berraies et al. (2014) found that centralisation is a negatively related to combination.The result is similar to Choi (2002), Lee and Choi (2000), and Migdadi (2005) with combination point of view. But Berraies et al. (2014) found that formalisation has a positive impact on combination.Similarly, the study result is consistent with Choi (2002), Lee and Choi (2000), Berraies et al. (2014) and Migdadi (2005) from information technology viewpoint.

In addition, the study results have revealed the culture as the most vital enabler of knowledge creation combination. Thus, building and supporting a culture which rewards and encourages employees for seeking, sharing, formalising and creating knowledge attributes will most probably lead to the successful capture, absorb, creation and implementation of knowledge management.

\section{REFERENCES}

Alavi, M., \&Leidner, D. E. (2001). Knowledge management and knowledge management systems: Conceptual foundations and research issues. MIS Quarterly, 25(1), 107-136.

Ardichvili, A., Maurer, M., Li, W., Wentling, T., \&Stuedemann, R. (2006). Cultural influences on knowledge sharing through online communities of practice. Journal of Knowledge Management, 10(1), 94-107. 
Bennett, R., \& Gabriel, H. (1999). Organizational factors and knowledge management within large marketing departments: An empirical study. Journal of Knowledge Management, 3(3), 212-225.

Berraies, S., Chaher, M., \&Yahia, K. B. (2014). Knowledge management enablers, knowledge creation process and innovation performance: An empirical study in Tunisian information and communication technologies sector. Business Management and Strategy, 5(1), 1-2

Bolloju, N., Khalifa, M., \& Turban, E. (2002). Integrating knowledge management into enterprise environments for the next generation decision support. Decision Support Systems, 33(2), 163-176.

Brown, S. J., \&Duguid, P. (2000). Balancing act: How to capture knowledge without killing it. Harvard Business Review, 78(3), 73-80.

Chalise, M. (2011). Knowledge management: A comparative study of public and private commercial banking sector undertakings in Nepal. (Doctoral dissertation, Tribhuvan University, 2011).

Chase, R. L. (1998). The people factor. People Management, 22, 38.

Chaudhary, M. K. (2016). Strategic alignment of knowledge management for organizational performance in Nepal. (Doctoral dissertation, Tribhuvan University, 2016).

Choi, B. (2002). Knowledge management enablers, processes, and organization performance: An integration and empirical examination. ( $\mathrm{Ph}$. D. Thesis, Division of Management Engineering, Korea Advanced Institute of Science of Technology, 2002).

Cook, S. D. N., \& Brown, J. S. (1999). Bridging epistemologies: The generative dance between organisational knowledge and organisational knowing. Organisation Science10(4), 381-400.

Curley, K. F., \&Kivowitz, B. (2001). The manager's pocket guide to knowledge management. Massachusetts: HRD Press.

Davenport, T. H., \&Prusak, L. (1998). Working Knowledge. Boston: Harvard Business School Press.

Demarest, M. (1997). Understanding knowledge management. Long Range Planning, 30(3), 374-384.

Fahey, L., \&Prusak, L. (1998). The eleven deadliest sins of knowledge management. California Management Review, 40(4), 265-276.

Gold, A. H., Malhotra, A., \&Segars, A. H. (2001). Knowledge management: An organizational capabilities perspective. Journal of Management Information Systems, 18(1), 185-214.

Gupta, A. K., \&Govindarajan, V. (2000). Knowledge management's social dimension: Lessons from nucor steel. Sloan Management Review, 71-80.

Hopper, M. D. (1990). Rattling SABRE-new ways to compete on information. Harvard Business Review, 118-125.

Ichijo, K., Krogh, G., \&Nonaka, I. (1998). Knowledge enablers. In G. Krogh, J. Roos, \& D. Kleine (Eds.), Knowing in companies (173-203). Thousand Oaks, CA: Sage.

Jeng, D. J. F., \& Dunk, N. (2013). Knowledge management enablers and knowledge creation in ERP system success. International Journal of Electronic Business Management, 11(1), 49-59.

Kandel, L. R. (2015). Knowledge management in Nepalese Telecom Industry. (M. Phil. Thesis, Tribhuvan University, 2015).

Kreitner, R., \&Kinicki, A. (1992). Organizational behaviour. Homewood, II, Richard D. Irwin.

Kuhlen, R. (2003). Change of paradigm in KM - Framework for the collaborative production and exchange of knowledge, IFLA publications, 1-19.

Lee, H., \& Choi, B. (2000). Knowledge management enablers, processes and organizational performance: An integration and empirical examination. Retrieved from http://cis.kaist.ac.kr/Research/file/128.pdf

Lee, H., \& Choi, B. (2003). Knowledge management enablers, processes and organizational performance: An integrative view and empirical examination. Journal of Management Information System, 20, 179-228.

Leonard-Barton, D. (1995). Wellsprings of Knowledge: Building and Sustaining the Sources of Innovation. Boston: Harvard Business School Press.

Li, Y. H., Huang, J. W., \& Tsai, M. T. (2009). Entrepreneurial orientation and firm performance: The role of knowledge creation process. Industrial Marketing Management, 38, 440-449.

Migdadi, M. M. (2005). An integrative view and empirical examination of the relationships among knowledge management enablers, processes and organizational performance in Australian Enterprises, (Ph. D. 
Dissertation, School of Economics and Information Systems, University of Wollongong, 2005).

Mohamed, M., Stankosky, M., \& Murray, A. (2006). Knowledge management and information technology: Can they work in perfect harmony? Journal of Knowledge Management, 10(3), 103-116.

Narasimha, S. (2000). Organizational knowledge, human resource management, and sustained competitive advantage: Toward a framework. Competitiveness Review, 10(1), 123-135.

Ndlela, L. T., \&Toit, A. S. A. (2001). Establishing a knowledge management programme for competitive advantage in an enterprise. International Journal of Information Management, 21, 151-165.

Nejatian, M., Nejati, M., Zarei, M. H., \&Soltani, S. (2013). Critical enablers for knowledge creation process: Synthesizing the literature. Global Business and Management Research: An International Journal, 5(2\&3), 105-119.

Nelson, K. M., \&Cooprider, J. G. (1996). The contribution of shared knowledge to IS group performance. MIS Quarterly, 20(4), 409-429.

Nevis, E., Anthony, D., \& Gould, J. (1995). Understanding organizations as learning systems. Sloan Management Review, 73-85.

Nonaka, I. (2008). The knowledge creating company. Harvard Business Review.

Nonaka, I., \& Konno, N. (1998). The concept of Ba: Building a foundation for knowledge creation. California Management Review, 40(3), 40-54.

Nonaka, I., \& Takeuchi, H. (1995). The knowledge-creating company: How Japanese companies create the dynamics of innovation. Oxford: Oxford University Press.

Nonaka, I., Byosiere, P., Borucki, C., \& Konno, N. (1994). Organizational knowledge creation theory: A first comprehensive test. International Business Review, 3(4), 337-351.

Nonaka, I., Toyama, R., \& Nagata, A. (2000). A firm as a knowledge-creating entity: A new perspective on the theory of the firm. Industrial and Corporate Change, 9(1), 1-20.

O’Dell, C., \& Grayson, J. (1999). Knowledge transfer: Discover your value proposition. Strategy and Leadership, 27(2), 10-15.

Paulus, P. B., \& Yang, H. C. (2000). Idea generation in groups: A basis for creativity in organisations. Organisational Behaviour and Human Decision Processes, 82(1), 76-87.

Quinn, J. B., Anderson, P., \& Finkelstein, S. (1996). Managing professional intellect: Making the most the best. Harvard Business Review, 71-81.

Raven, A., \&Prasser, S. G. (1996). Information technology support for the creation and transfer of tacit knowledge in organizations. Association for Information Systems 1996 Americas Conference. Retrieved fromhttp:// hsb.baylor.edu/ramsower/ais.ac.96/papers/RAVEN.htm

Robbins, S. P. (1998). Organisationalbehaviour: Concepts, controversies, applications (11 th ed.). USA: Prentice Hall.

Robbins, S. P., Millet, B., Cacioppe, R., \& Waters-Marsh, T. (2001). Organisational Behaviour: Leading and Managing in Australia and New Zealand. (3rd ed.). Malaysia: Prentice Hall.

Sawhney, M., \&Prandelli, E. (2000). Communities of creation: Managing distributed innovation in turbulent markets. California Management Review, 42(4), 24-54.

Takeuchi, H., \&Nonaka, I. (2004). Knowledge creation and dialectics. Hitotsubashi on knowledge management. John Wiley \& Sons, Asia Pte Ltd.

Vaccaro, A., Veloso, F., \& Brusoni, S. (2009). The impact of virtual technologies on knowledge-based processes: An empirical study. Research Policy, 38(8), 1278-1287.

Wenger, E., \& Snyder, W. (2000). Communities of practice: The organisational frontier. Harvard Business Review, 39-145.

Zaltman, G. (1986). Knowledge utilization as planned social change. In G. Beal, W. Dissanayake, \& S. Konoshima (Eds.), Knowledge Generation, Exchange and Utilization (433-462). Boulder, CO: The Westview Press.

Zucker, L. G., Darby, M. R., Brewer, M. B., \& Peng, Y. (1996). Collaboration structures and information dilemmas in biotechnology: Organization boundaries as trust production. In R. M. Kramer, \& T. R. Tyler (Eds.), Trust in Organizations: Frontiers of Theory and Research (90-113). Thousand Oaks, CA: Sage. 